\title{
The Communicative Functions of Nominal Group Expressions in Selected Nigerian Newspaper Headlines
}

\author{
Samuel Edem \\ Department of English \\ Nigeria Police Academy \\ Wudil, Kano State, Nigeria
}

\begin{abstract}
Despite the substantial scholarships on nominal group as grammatical category in English showcasing its traditional functions in grammatical structures, not much has be done on this grammatical category from the perspectives of media discourses. This study, from a linguistic perspective, examines the communicative functions of nominal group expressions in selected Nigerian newspaper headlines. The study aims at achieving two viable goals. Firstly, it showcases nominal group expressions as intentional constructive language types deployed by newspaper headlines to initiate discourse, sustain and shape the views of the readers on the issues propagated. In other words, it ascertains that nominal groups perform some pragmatic acts that are absolutely revealing; and secondly, it accentuates that nominal groups in print media discourses are ideologically driven. 18 headlines are purposively selected from Daily Trust, Vanguard, The Nation, The Punch, The Guardian and Daily Sun, and the nominal group patterns are examined for their grammars, rhetorical peculiarities and functions. The study deploys the theoretical approaches of Systemic Functional Linguistics alongside Pragmatics and Critical Discourse Analysis for the analysis of texts. Research such as this will contribute not only to the understanding of the ideological role of the English nominal group in media discourses but also has fundamental teaching implications and awareness of the functional status of language in general, and news discourse in particular.
\end{abstract}

Keywords: English nominal group, Media discourses, Nigerian newspaper headlines, ideology, Systemic functional linguistics, Pragmatics, Critical discourse analysis.

\subsection{Introduction}

Communication informs and creates awareness. It motivates and reinforces behaviours and the mass media prove to be formidable channels in this direction. Communication is only successful when an interpreter assigns values to the meanings intended by the writer. Hence, communication necessitates the ability of the writer to articulate his message in very clear terms so that the receiver can decode the content very well. The more appropriate and effective the language of the message is, the more the receiver derives satisfying productive and meaningful relationships both in personal, public, social, political and educational lives. We understand and comprehend the world through language, thus, if we communicate using the right language our sense of social reality will accordingly be effective. Language plays a formidable role in communication because it is related to our perceptions of social reality. It is a system of communication and communication in turn is seen as a tool in the hands of writers in solving problems. This means that the production of a written text is a social process which entwines the interaction between the writer and the reader.

Malmkjær (1991:141) describes language as an "instrument by means of which people can enter into communicative relations with one another." To Halliday (1978), language is seen primarily as a 'social semiotic' resource for meaning, through it, humans negotiate, construct, and change the nature of social experience. By this, language becomes a fundamental phenomenon for the communication of ideas, knowledge and intentions amongst human beings. The knowledge of language use is the ability of how to use it effectively. This implies, channeling it to do what one wants it to do in the appropriate context. This is pragmatic act in its entirety. A writer uses language to achieve his aim, this infers that the hearer in turn, is expected to understand and interpret the message or utterance of the writer in a particular way.

It is important, therefore, that the messages designed for the media according to Lesley (2002) be acceptable, compatible intense, visible, pervasive, variegated and persuasive. 
According to Okunna, et al (2002:274), the information function of the Mass Media is all embracing and indispensable for the meaningful existence of members of society. Through their various contents, the mass media collect, store, process and disseminate news, data, pictures, facts, messages, opinions and comments which members of the public require in order to react knowledgeably to personal, environmental, national and international conditions, as well as to be in a position to take appropriate decision. Anything that is said or written about the world is articulated from a particular ideological position and as such we tend to think that newspaper reporters, opinion leaders, copywriters and politicians and so on can affect us through their use of language. The question is how does it happen exactly? Systemic linguistics, pragmatics and critical discourse analysis provide us with language theories for explaining this, considering the social and political contexts in which texts are produced and read.

In linguistics, language is analyzed from its structure and function. This implies that there are two basic facts about language. Firstly, language is viewed as a high degree of organization that appears to our perceptions. Secondly, language is often used by people to do things, mean things, and achieve things such as questioning, declaring, given instruction or order, persuading wreathe with diverse forms of illocutionary acts. Nominal groups(henceforth NGPs) as language types have come to be accorded a fundamental place in the repertoire of newspaper headline discourses.

English is a highly nominalized language and lexical meaning is largely carried in nominal group, consequently, the newspaper headline is no exception in its usage. NGPs have become viable mechanisms in news producing processes, selections, interpretations, and presentations of events to the audience as well as in constructing realities in a manner corresponding to the underlying ideologies of the reporters. NGP as a language type is one of the principal channels through which meaning is mobilized in the social world via the media.

Newspaper headlines act as forerunners to news reports. Particularly, they reveal the social, cultural and national representations circulating in a society at any given time. They reach an audience considerably wider than those who read the news story. Taiwo (2004: 324) submits that headlines are strategically used by newspaper editors to make an impact on readership. According to him, editors choose emotive vocabulary, rhetorical and graph logical devices to achieve this. NGPs prove to be one of the valuable choices in this perspective. They prove to be effective-inducing strategies or quick linguistic mechanisms at the disposal of the reporters to initiate discourse, sustain and shape the views of the readers on the issues propagated.

The way a writer communicates with language is determined by social structures. Whatever informs a text can be said to be the idea behind the context of the text. Hence, the relationship between language and ideology is established, since our attitudes, beliefs and orientation cannot be separated from the language we use. Ideologies are based on a set of beliefs and attitudes shared by a group, class or society and they are often expressed through language. Anything that is said or written about the world is articulated from a particular ideological position. In this way, every instance of language is a reflection of the prevailing discursive and ideological system in the society where it is used. Newspaper reporters use NGPs as linguistic tropes to project their viewpoints and to suit the ideological expectations of their audience.

\subsection{The Nominal Group: An Overview}

Creativity is a salient feature of human language and group type constitutes a unique aspect of this overture. In systemic functional linguistics, the linguistic feature is placed third on the hierarchy of the grammatical units in the language. Thompson (2000: 166) affirms that group constitutes the immediate structure after clause in the rank ladder. Just as the clause has functional slots (e.g. Subject; Actor; Theme) which are filled by groups and phrases, so does this grammatical element. It can be analyzed in terms of the functional slots or properties that it offers. Some linguists believe that a group is synonymous to a phrase in other grammatical model (Crystal, 2008); while others assert that a group is not a phrase. To them, a phrase is different from a group in that, the former is a contraction of a clause, whereas the latter is an expansion of a word (Arnold, 1985: 159). In all, group is as fundamental as any other level of linguistic descriptions because of its mutual inclusiveness.

In systemic functional linguistics, a nominal group is a group of words which expresses an entity. It is "typically a group with a noun (or pronoun) as its head." (Bloor \& Bloor 2004: 31). The nominal group can function as subject and complement in a clause and can also function as the complement of a preposition in a prepositional phrase. In systemic functional linguistics, three functional components are realized in language and the group structure is interpreted in terms of the ideational function. 
The ideational component in group structure is divided into two: experiential and logical. The logical component defines the logical-semantic relations in the group and the relationship in the nominal group is that of modification. The element before the head is called the premodifier and that which comes after the head is the postmodifier often inferred as qualifier. Therefore, on the logical component, three positions can then be identified: premodifier, head and postmodifier- $(\mathrm{M}) \mathrm{H}(\mathrm{Q})$, with ' $\mathrm{H}$ ' as obligatory element while ' $\mathrm{M}$ ' and ' $\mathrm{Q}$ ' are optional elements. Therefore, there are four structural possibilities of the nominal group, these are: the ' $H$ ' type which is made up of only a nominal head, the 'MH' type, with modification(s) before the head, the 'HQ' type with qualification(s) after the head and the 'MHQ' type with all the basic elements present (i.e. the pre and post modifiers, plus the head).

Halliday (2004: 320) identifies six experiential functions in a nominal group and these are: Deictic, Numerative, Epithet, Classifier, Thing and Qualifier. The elements which realize the premodifier on the logic sub-function are divided on the basis of their experiential roles into deictic, numerative, epithet and classifier. Deictic has a pointing function and is usually realized by determiner, a possessive noun or a possessive pronoun. Deictic element indicates whether or not some specific head is intended; and if so, which one. Hence, deictic can be specific or non-specific. Specific deictic may specify the intended head by one of two possible ways: either demonstratively by means of a reference to some kind of proximity to the speaker using 'this', 'these' (Morley, 1985:47), or by possession, by reference to a person as defined from the standpoint of the speaker (my, your, our, his, her, its, their; and so on) . All these have the functions of identifying a particular head that is being referred to. Non-specific deictic on the other hand, signals that the hearer or reader is not assumed, or does not need to be familiar with the specific identity of the head at that point (Thompson, 2000: 182). It then assumes that the deictic slot is not needed for identification, rather it is used instead to indicate what quantity of head is involved. Examples are 'all', 'some', 'non', 'both' etc.

Numerative can be realized by the word class numeral which includes cardinal and ordinal numbers. In other words, it indicates the number or quantity of the Head, either in exact terms, 'three', 'twenty', or in inexact terms, 'many', 'much'; or it specifies order, 'first', 'fifth" (Halliday, 1994:183). Epithet indicates the features of the modified items. Epithet indicates some quality of the head and is typically realized by adjective e.g. old, long, blue, fast. Epithet may be an expression of the speaker's subjective attitude towards the head, e.g. splendid, silly, fantastic, or it is an objective property of it, e.g. red, tall, huge (Morley, 1985:89). Classifier has the function of sub classifying the modified item into a subclass of such item. Whereas thing conflates with the head and is usually realized by a noun or pronoun. Qualifier (the element which follows the thing) conflates with premodifier and is usually realized by prepositional phrases and embedded clauses. Creative writers like news reporters deploy nominal group as choice from their linguistic list in order to project their ideas. This praxis contributes to the general meaning they try to convey.

\subsection{Methodology}

The data for this study consists of eighteen (18) headlines collected from six Nigerian newspapers published between 2011, 2015, 2016 and 2017 respectively. The papers are Daily Trust, Vanguard, The Nation, The Guardian, The Punch and Daily Sun, and the nominal group patterns were examined for their grammatical peculiarities and communicative functions. The study adopts the method and insight of systemic functional linguistics alongside pragmatics and critical discourse in the description, interpretation and analysis of the selected NGP headlines, indicating their typologies, surface structures as well as how they reflect the attitude of the reporters. Through these theoretical approaches, NGPs of newspaper headlines are revealed not only as forms of social actions but as linguistic forms characterized by ideological underpinnings.

\subsection{Conceptual Clarification}

Here, we will briefly explain the linguistic approaches adopted by this study. Systemic functional linguisticsas a concept is a linguistic description propounded by M.A.K Halliday. To Halliday, grammar is described as system not as rules. His argument is that every grammatical structure or communicative act involves choices from a describable set of options for the construction of meaning (Halliday, 1985). According to Halliday, the explanation of how language works needs to be grounded in a functional analysis since language had evolved in the process of carrying out certain critical functions. To him, language or discourse functions operate within the context of situation. 
In a newspaper discourse, for instance, the transmission of a world view or structuring of experience as this study intends to showcase, functions through the communicative mode espoused by the reporter.

Pragmatics, on the other hand, emerges as a result of the need for analyzing a text with more comprehensive understanding. Pragmatics focuses on the communicative use of language conceived as intentional human action. "Intention" has become the focus of various disciplines; for example, psychologists study the text producer's intention to guide the consciousness of the hearer. According to Onuigbo (2007:317), the concept was first developed by Pierre in 1931 and was amplified by Dewey. However, the origin of modern pragmatics is attributable to Charles Morris (1938), a British philosopher who was concerned with the study of the science of signs or "semiotics". According to Morris, semiotics consisted of three (3) broad branches namely: syntax, semantics and pragmatics. Syntax or syntactic deals with the relations of sign to one another, semantics deals with the relations of signs to objects while pragmatics deals with the relations of signs to interpreters (Morris, 1938:19). This establishes the fundamental place of language study in pragmatics.

In an attempt to define pragmatics, quite a good number of critics have thrown more light on it. Leech \& Short (1981:290) see pragmatics as "the investigation into that aspect of meaning which is derived not from the formal properties of words, but from the way in which utterances are used and how they relate to the context in which they are uttered". Take note of the word "utterances" not necessarily sentences. Kempson (1997:8) on pragmatics declares that it delineates how a speaker of a given language can use the structure of the language to convey messages which do not necessarily have any relation to the linguistic content of the structure used. To Onuigbo (2007:318), pragmatics accounts for what people use language to do and the linguistic features employed in doing it.

However, in recent times, extended researches in cultural studies and social discourse have argued in favour of discourse pragmatics rather than the traditional linguistic pragmatics. Fairclough (1989) argues that rather than one seeing language use as an individual's strategy of encoding meaning to achieve some particular effects on the hearer or reader, one should be concerned with the fact that social conventions and ideologies define people's roles, identities and language performances; people simply communicate in some particular ways as the society determines and that people can manipulate language to achieve certain purposes because in some circumstances they are actually ruled by social conventions. This line of thought justifies our use of critical discourse analysis (henceforth CDA)as supportive framework in this study.

CDA therefore, draws on poststructuralist discourse theory and critical linguistics. It focuses on how social relation, identity, knowledge and power are constructed through written and spoken texts. The techniques of CDA are derived from various disciplinary fields, such as pragmatics and speech acts theory, systemic functional linguistics and critical linguistics. Pragmatics and speech acts theory see texts as forms of social actions that occur in complex social contexts. Systemic functional linguistics shows how linguistic forms can be systematically related to social functions. CDA uses analytical tools from these disciplines to address issues on class, power, gender, race and culture.

\subsection{Data Presentation and Analysis}

The main purpose of newspaper discourses is to gain the attention of the public to become interested in news reports. This is normally done through the creation of attractive contexts via headlines, and NGP seems to be a quick way of achieving this. NGPs prove to be functional texts; hence, reporters deploy them for the readers' consumption in order to accomplish something. Nonetheless, each newspaper manipulates this construct from different perspectives. The following examples are illustrative:

Headline 1: Private jets galore at IBB's daughter's wedding Daily Trust, Saturday May 13, 2017. P3.

The surface structural categorization of the NGP headline is:

\begin{tabular}{|l|l|}
\hline Private jets galore & at IBB's daughter's wedding \\
\hline $\mathbf{M}^{(\mathbf{( e )}} \mathbf{M}^{\mathbf{( C )}} \mathbf{H}$ & $\mathbf{Q}^{\text {Adverbial })}$ \\
\hline
\end{tabular}

Headline 1, pragmatically, expresses the reporter's negative evaluation of the context. The reporting act is tactical. Tact proves to be one of the most appropriate ways in communicating or reporting a message that projects the speaker's intention. According to Adegbite (2000), tact or tactics by implication, is a means of interpreting the 
discourse value of information encoded in a word or a phrase and its relationship with other linguistic items which precede or follow the items as well as some other non-linguistic factors of communication based on the communicative context of an utterance. To him, "discourse value" is simply the meaning which the speaker or writer expects his hearer/reader to decode or interpret. In this way, the meaning of a text is determined by the linguistic behaviour of the language context. Every instance of language use is produced from an ideological perspective and the choice of words is fundamental in providing readers with cues for interpreting events.

A close study of the headline reveals that the NGP is ideologically impelled. It unveils to the reader a context characterized by a raucous display of wealth. The ideology of the text is encoded in the $\mathrm{M}^{(\mathrm{e})} \mathrm{M}^{(\mathrm{c})} \mathrm{H}$ structure'Private jets galore'. The lexical term 'galore' in the context sounds comical. It is fashioned by the writer in such a way that it unmasks a show of reckless abundance. Indirectly, the discourse tactically incites the reader, making him or her arrive at his or her own judgment on these set of participants at the wedding. The choice of words, actually, can define how we perceive actions and the intentions of participants in an event, thereby, comprehending the message that the producer of the text intends the readers to perceive or receive.

\section{Headline 2: THE AMBODE SIGNATURE ...}

Driving the Lagos dream. Sunday Sun, July31, 2016 P25

For Headline 2, the surface structural categorization of the NGP is :

\begin{tabular}{|l|l|}
\hline THE AMBODE SIGNATURE & Driving the Lagos dream \\
\hline $\mathbf{M}^{(\mathbf{d})} \mathbf{M}^{(\mathbf{c}} \mathbf{H}$ & $\mathbf{Q}^{\text {(comp) }}$ \\
\hline
\end{tabular}

A close study of headline 2 earmarks that the writer's ideology is nested in the grammatical metaphor 'The Ambode Signature'. Grammatical metaphor is one of the key concepts in systemic functional linguistics and metaphorical pragmatic-acts mean something other than their literal sense in some sense of meaning as in the headline described. The lexical item 'signature' is a representation of a person's identification. In the context, it carries the content of the message which the reporter tries to convey. The fore grounded element assumes that the figure hasan identifiable characteristic or mark. Thus, his endorsement by Political Players of Lagos state to succeed Fashola is worthwhile. This worthwhileness is vividly captured in the second half of the headline framed 'driving the Lagos dream'. The verbal structure establishes the governor's vigorousness in seeing Lagos state'sdreams come true. In view of this, the entire headline eulogizes the incumbent governor of Lagos state for a work well done. A critical insight into the deictic modifier 'the' indicates some level of knowingness in terms of trust and capability, and from the 'Q' element- 'driving the Lagos dream', the meaning of the context is conceived that the present governor has not failed those who endorsed him out of trust as Fashola's successor. The headline is indeed a pro-government headline.

Headline 3: The Tinubu Factor in Yoruba and Nigeria affairs The Guardian, Friday May 19, 2017 P18.

For Headline 3, the surface structural categorization of the NGP is:

\begin{tabular}{|l|l|}
\hline The Tinubu Factor & in Yoruba and Nigeria affairs \\
\hline $\mathbf{M}^{(\mathbf{d})} \mathbf{M}^{(\mathbf{c})} \mathbf{H}$ & $\mathbf{Q}^{\text {(comp) }}$ \\
\hline
\end{tabular}

Headline 3 has the same structural constituent with headline 2. The communicative act is expressive in its ideological essence. There are three things to note concerning the language of the headline. Firstly, it is progovernment. Secondly, the notion of its compositionality, and thirdly, the communicative act or pragmatic act is expressively advocated, that is, it reveals the speaker's intention on the figure being spoken about. The definite article, 'the' here, also shows some level of definiteness or knowingness. The speaker proves to know the figure he projects. However, definiteness is only a measure of uniqueness within the mind of the speaker and perhaps the listener or reader. Nevertheless, a critical study of the conceptual interpretation of the grammatical metaphor 'The Tinubu factor' clarifies why the 'Tinubu influence' is needed in the polity of the Nigerian nation. To the writer, the leadership problem in the nation demands that we pay attention to rescuing what is handed over to us in terms of leaders and those who can achieve what is needed towards nation building. To him, Tinubu's significance straddles not only the Yoruba but also the nation at large. He is one leader out of many who has been involved in the turbulence of making Nigeria work as a nation. For instance, any attempt at narrating the turning point of the 
governance story that transformed Lagos, would have to factor the Tinubu governorship years into the Lagos governance history. With this, the writer's ideology is deep-seated in the grammatical metaphor' The Tinubu factor'. The use of grammatical metaphor seems to be a common trait by headline tabloids.

Here, it helps to propel the writer's ideology or subjective view on the figure he speaks about. The NGP headline is more of eulogy than vilification.

Headline 4: 1963 Constitution ideal Grundnorm, says Middle Belt

The Guardian, Sunday September 10 2017. P2.

For Headline 4, the surface structural categorization of the NGP is:

\begin{tabular}{|l|l|}
\hline $1963 \quad$ Constitution & ideal Grundnorm, \\
\hline $\mathbf{M}^{(\mathbf{n})} \mathbf{H}$ & $\mathbf{Q}^{\text {(comp) }}$ \\
\hline
\end{tabular}

Headline 4 is intentionally designed with a direct speech method to gain some level of potency. Two things capture our fancy. Firstly, the NGP headline is an epitome of a declaration act. Secondly, the entire textis characterized by implicit assumption that unveils the intent of the speaker. To the speaker, the present constitution in place is lopsided. Hence, for the Nigerian nation to be sane and for the interest of the people to be adequately represented in the Presidential System of Government, the nation must return to the 1963 constitution. The headline can be argued on one hand as an elitist headline and on the other hand as anti-government headline. Nevertheless, our interest is the language used and as well as what it advocates. The advocates of this headline see 1963 constitution which was before the coup that brought late General AguyiIronsi to power in Nigeria as a solution to diverse acrimonies presently plaguing the country or as a better option for the restructuring of the nation. The headline definitely serves the interest of those who are opting for regionalism or true federalism.

Headline 5: Red Card to Herdsmen Daily Sun Tuesday, November 29, 2017. P22.

The surface structural categorization of the NGP headline is:

\begin{tabular}{|l|l|}
\hline Red Card & to Herdsmen \\
\hline $\mathbf{M}^{(\mathbf{e})} \mathbf{H}$ & $\mathbf{Q}$ \\
\hline
\end{tabular}

The reporting act here is that of declaration. In pragmatics, speech is often goal-oriented (i.e. the meaning which the speaker or writer intends to communicate). The ideological underpinning of the headline is enclosed in the lexical items "red card" having the $\mathrm{M}^{(\mathrm{e})} \mathrm{H}$ structure. The term is associated with the field of sports, specifically, football and it is often given to a player when he is guilty of a violent conduct. In the discourse context, the term is deployed by the reporter to indicate vehement dismissal as well as a violent protest to accommodate anymore infringement. The term intensifies the context. The NGP headline seems to assume that the declaration is based on a court verdict or an established consensus by those who are involved, whose rights have been infringed for a long time. So, 'red card' designates that the herdsmen should vacate the land in question and the speaker needs not to waste any time in declaring it publicly. The declaration may not be far from the recent claims by people on the activities of herdsmen in their communities. The headline is a prototype of a populist headline.

Headline 6: Herdsmen attack capable of breaking Nigeria- Falae

$$
\text { Saturday Sun, September 16, 2017. P11 }
$$

The surface structural categorization of the NGP headline is :

\begin{tabular}{|l|l|}
\hline Herdsmen attack & capable of breaking Nigeria \\
\hline $\mathbf{M}$ H & $\mathbf{Q}^{\text {(comp) }}$ \\
\hline
\end{tabular}

Headline6 is another illustrative example of a populist headline that is illocutionary assertive. The purpose of assertive act is to convey information. Assertive acts are not constrained as far as their propositional content is concerned. According to Havertake (1969:.18), they may express "any proposition". Assertive acts may include amongst others, stating, suggesting, boasting, complaining, and claiming. The communicative potency of the headline is encapsulated by three viable implications. Firstly, the headline shows that there is an attack perpetuated by herdsmen, secondly, the attack is incessant, that is, it has continued overtime, and thirdly, it discloses to the reader government's inability to curb the mayhem caused by this sect. The headline serves as a 
red light; a note of warning or a reminder to the government the need to take prompt decisions in eradicating the pandemonium caused by herdsmen which is capable of breaking the nation.

Headline 7: Deployment of soldiers in Kanu's house illegal— Falana

The Punch, Thursday, September 14, 2017. P 20.

The surface structural categorization of the NGP headline is :

\begin{tabular}{|c|l|}
\hline Deployment & of soldiersin Kanu's house illegal \\
\hline $\mathbf{H}$ & $\mathbf{Q}^{\text {(comp) }} \mathbf{Q}^{(\mathbf{c o m p})}$ \\
\hline
\end{tabular}

This NGP headlines is structured as a caveat. It serves as an indication of warning to the federal government on the recent action or arrest meted on Kanu, the leader of IPOB (indigenous people of Biafra). The speaker sees the action of the government through the use of soldiers as brute force and uncalled for. To him, such act is illegal and unconstitutional. The NGP headline divulges that the arrest of Kanu is not within the jurisdiction of the army but the police. The lexical item 'illegal' has lots of pragmatic connotations as deployed in the context; hence, the entire context is weaved around it. With this, the communicative function of the lexical item 'illegal' can be interpreted pragmatically as a call for a demilitarization of the country.

Headline 8: $\quad$ Biafra referendum not Possible - OkoObla

Saturday Sun, July 1 2017. P48.

The surface structural categorization of the NGP headline is :

\begin{tabular}{|l|l|}
\hline Biafra Referendum & not possible \\
\hline $\mathbf{M ~ H ~}$ & $\mathbf{Q}^{\text {(comp) }}$ \\
\hline
\end{tabular}

The proposition in headline 8 is adversative because it signals a contrariety. In other words, it is negative in its assertion as some linguists would put it. Notwithstanding, the NGP is structured to gain attention and also to impact meaning on readership. To the speaker, the demand for a referendum on a separate state of Biafra is constitutionally impossible as captured by the MHQ structure. The headline is a pro-government headline with a direct speech method that should have read: 'Biafra Referendum $<$ is $>\phi$ not possible', but there is the elision of the copula verb 'is' to have the headline function as NGP. This linguistic manipulation is a sure index that NGP is a language type.

Headline 9: Nigeria's break up possible - MbazulikeAmaechi

The Sun, March 25 2017. P42.

The surface structural categorization of the NGP headline is :

\begin{tabular}{|c|c|}
\hline Nigeria's break up & Possible \\
\hline $\begin{array}{ll}\mathrm{M} & \mathrm{H} \\
\end{array}$ & $\mathrm{Q}^{\text {(comp) }}$ \\
\hline
\end{tabular}

This NGP headline is illocutionary assertive projected as a warning or proviso in the context. There are two interesting things about this headline. Firstly, it is anti-government. Secondly, it is a counter headline to that of 8 . The NGP directly enacts the statement by a foremost nationalist and outspoken elder statesman, Chief Mbazulike Amaechi whose position and argument reveals to the reader the possibility of Igbo secession. His proposition is necessitated or impelled by the present humiliation and threat on the Igbo nation. To him, such secession is tenable unless the needful is addressed. Pragmatically, the NGP headline becomes an indicator of warning to the government to address the present agitation of the people of Biafra.

Headline 10 : Anti-Buhari Forces behind Calls for Restructuring-Ex-Minister Oyelose Saturday Sun, July 1, 2017. P44.

The surface structural categorization of the NGP headline is

\begin{tabular}{|l|l|}
\hline Anti-Buhari Forces & behind calls for restructuring \\
\hline $\mathbf{M} \quad \mathbf{H}$ & $\mathbf{Q}^{\text {(comp) }} \mathbf{Q}^{\text {(comp) }}$ \\
\hline
\end{tabular}


Headline 10 is a pro-government headline. This is obvious in the language employed. The speech is a direct type. The statement of the speaker evinces that people who cannot withstand Buhari's anti-corruption war are those singing the praises of restructuring, thereby disintegrating the nation.

Headline 11: Our Economy in Trouble

Vanguard, Thursday July 7 2011. P1

The surface structural categorization of the NGP headline is :

\begin{tabular}{|l|l|}
\hline Our Economy & in Trouble \\
\hline $\mathbf{M ~ H}$ & $\mathbf{Q}^{\text {(comp) }}$ \\
\hline
\end{tabular}

The reportage of headline 11 is assertive as well as anti-government. The language of the NGP is intentionally trump up to create conflict. It is constructed in such a way that the reader feels privy to viable information concerning the nation. The NGP headline attacks and exposes the government for their ineptitude and inability to manage the country's resources. One major feature of power relation on the pages of the newspaper is the power of persuasion which is often used in the construction of headlines. A critical analysis of headlines in print discourses shows that all of them set out to arouse the attention of readers, but with focus on different aspects of the news. Here, the assertiveness is dramatically constructed to keep the tension of the polity high as the state of the economy is imported to the fore of the public. Indirectly, the headline is earmarked with condemnation. Pragmatically, the NGP headline can be taken on one hand, as a reminder to the government to man up to its responsibility if the country's economy must be healthy. On the other hand, it can also mean that the present government is corrupt, and as such the situation is helpless.

Headline 12: The Southern Kaduna Killings: The inside story

Daily Trust, Saturday, January 14, 2017. P4-5.

The surface structural categorization of the NGP headline is :

\begin{tabular}{|c|c|c|}
\hline The Southern Kaduna Killings & The ins & story \\
\hline MM & M M & 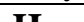 \\
\hline
\end{tabular}

Headline 12 serves the interest of the government. One interesting thing about this headline is that it has a pointer. Headlines with pointers are those headlines that have one or more words that create in the reader the awareness of the context in which the comments that follow are being made. There are two parts to the headline - the given information and the comment that follows (Taiwo, 2004:326). This headline has an historical background. The information given by the headline capped in $\mathrm{MMMH}$ on one hand and $\mathrm{MMH}$ on the other hand, certainly presupposes certain stock of knowledge that deters anybody who is not familiar with the field of reference from decoding the content. The religious setting in the country assumes that the North is largely dominated by Moslems, while the South by Christian. Several issues are naturally woven around this dichotomy, which often precipitate religious riots at the slightest opportunity like the headline above. Consequently, the reader who has been following the trend of events in the media understands or knows who the headline is trying to pacify. The idea is to correct the misconception that the Kaduna riot was intentionally plotted to eliminate the Christians in Southern Kaduna. Hence, this headline seems to be a means through which those who have lost trust and hope in the government because of the mayhem will be pacified. It is also published to cover up government lapses of not responding quickly to the crisis before it degenerated.

Headline 13: Al-Mustapha a pathological liar

Sunday Sun, June 11, 2017. P50.

The surface structural categorization of the NGP headline is :

\begin{tabular}{|l|l|}
\hline Al-Mustapha & a pathological liar. \\
\hline H & $\mathbf{Q}^{\text {(comp) }}$ \\
\hline
\end{tabular}

The NGP headline of 13 interests us because of its assertive constructiveness. The information conveyed by the NGP headline is informing and jolting. The headline is a direct attack by Ayo Opadokun, a defunct NADECO (National Democratic Coalition) scribe/ secretary. He chastises the then National Security Officer of late SaniAbacha, Major Hamza Mustapha over recent disclosure of his possession of a video clip on how MKO Abiola died. The NGP headline seems to be enveloped with face threatening act (FTA).If you say things that 
make people embarrassed or uncomfortable, or something that threatens another person's self-image, you are said to have employed a face threatening act. The act deployed here also indicates that the speaker has some measure of power or superior social power than the person being addressed. Pathology, from medical sciences has to do with the study of the essential nature of diseases. Hence, to classify a person a pathological liar implies that one would likely treat anything uttered by that person with skepticism and wariness. This is the implication of the headline that Al-Mustapha is infested with a 'lie disease' and that the nation should discard his claim or whatever he says.

Headline 14: $\quad$ EFCC Bose a Perennial Offender ----DSS Saturday Sun, March 25, 2017. P9.

The surface structural categorization of the NGP headline is :

\begin{tabular}{|l|l|}
\hline EFCC Bose & a Perennial Offender \\
\hline $\mathbf{M} \quad \mathbf{H}$ & $\mathbf{Q}^{\text {(comp) }}$ \\
\hline
\end{tabular}

The NGP of headline 14 is a direct speech. The use of the hyphen is an indicator that the DSS is responsible for this. The NGP with MHQ type is equally confrontational and provocative. The illocutionary act here is declarative, although with some level of judgment. The integration of the lexical items anchored by the Qualifier (Q) shows that the offence has gone beyond mere accusation. It has become an established fact. The adjective 'perennial' showcases that the offence by the offender has persisted, so, he should be prosecuted or face legal trial. It is the ' $Q$ ' that anchors the declaration. There are two things about this headline. Firstly, it is intentionally structured to serve as a counter-headline, perhaps to debunk the stance or position of the presidency concerning the figure involved. Secondly, it is deliberately structured to redirect and garner the attention as well as the support of the reader or public against the figure in question. To the DSS (Department of State Security), the office of The Chairman of EFCC should be occupied by an impeccable character with proven integrity and capacity to lead the nation in the fight against graft in low and high places. Pragmatically, the NGP headline subsumes that the figure involved is not that kind of officer. Therefore, he should be discredited for the post.

Headline 15: Theatre of Flood at every drop

The Guardian, Friday May 12 2017. P10

The structure of the NGP headline is:

\begin{tabular}{|l|l|}
\hline Theatre & of flood at every drop \\
\hline H & $\mathbf{Q} \quad \mathbf{Q}^{\text {(AdV) }}$ \\
\hline
\end{tabular}

This is a populist headline represented by an expressive act of sharp criticism. The headline is metaphorical and topical. It unveils to the reader the gross negligence and ineptitude of the government to the environment. The language commands our empathy. The magnitude of the language in the context reminds us of one of these motion pictures that dramatize a scene that is pitiable, unbearable, devastating and painful. It showcases impassable roads after every drop of rain. Note the writer's usage of 'every drop' not down pour'. This is to indicate that even at the slightest form of rainfall; the roads are not motorable, much less when it pours heavily. The pragmatic act of the headline is that of condemning, criticizing and blaming. The lexical item which serves as an adverbial complement is imbued into the text to mock the government and also to indicate precision. It intensifies the context of what is being described. The NGP, overtly, captures the government as charlatans for being less concerned about the environment and the citizens.

Headline 16: Randy adults on rampage.

Saturday Sun March 25, 2017. P14.

The NGP structure is :

\begin{tabular}{|l|l|}
\hline Randy adults & on rampage \\
\hline $\mathbf{M}^{(\mathbf{c})} \mathbf{H}$ & $\mathbf{Q}$ \\
\hline
\end{tabular}

The reportage in headline 16is informative. Here, the NGP is deployed as a linguistic sign by the reporter to herald or designate a phenomenon of reality. Our definition of 'linguistic sign' in this study infers to any unit of language (morpheme,word,phrase, or sentence) deployed to signal objects or phenomena of reality. The metaphor 'randy adults' in the context is implied. In other words, it goes beyond mere name. Pragmatically, it infers 
lecherousness. The way people use language actually goes beyond what they mean. Here, the writer uses 'randy adults' to refer to persons given to sexual violence and addiction. The NGP is metaphorically foregrounded to become a language type or adage showcasing the alarming proportion of sexual assaults by men on under aged females and also for warning. Headline 17 and 18 x-ray NGPs that serve as anchors to performative phrases.

Headline 18: Buhari to Military: defeat ideologies of mindless killings

The Nation, Sunday September 17 2017. P8

The NGP structure is :

\begin{tabular}{|l|l|}
\hline Buhari & to Military defeat ideologies of mindless killings \\
\hline $\mathbf{H}$ & $\mathbf{Q}$ \\
\hline
\end{tabular}

Language, obviously, provides articulated means for differences in power in social hierarchical structures". (Ruth Wodak, (2001:11). Thus, the analysis of language is a great tool to investigate power relation such as dominance and inequality in media discourses. NGP as linguistic and discourse mechanism plays a fundamental role in the comprehension of headlines 17 and 18 respectively. Here, the NGP becomes an anchor to the acts. It helps the reader to know who gives the instruction and who takes the instruction or to whom the instruction is given. The directive act in headline 18 is that of command or order.

Directive actdoes have a purpose when the speaker has authority to what is said, if it does not have the authority, then,the execution of the instruction given to the addressee becomes invalid. Headlines 17 and 18 are examples of directive acts with different tones. Power is being exercised here. The given information which is the NGP with the HQ structure in headline 17, actually anchors what the speaker wants to be carried out, and this is projected in the performative phrase - 'defeat ideologies of mindless killings'. The metaphor 'ideologies of mindless killings' refer to enemies of the nations whose identities and motifs are unknown. To the speaker, such ideology should not be accommodated at all, but must be eliminated.

Headline 18: Buhari to lawyers: join fight against crooks

The Nation, August 23 2015. P1.

The surface structural categorization of the NGP headline is :

\begin{tabular}{|c|l|}
\hline Buhari & to lawyers \\
\hline H & $\mathbf{Q ~}^{\text {(comp) }}$ \\
\hline
\end{tabular}

For headline 18, the language use is polite unlike headline 17. To ensure success in the war against corruption, the addresser has obeyed the politeness principle which assumes that the interact ants behave politely to one another since people respect one another in an interactive speech event. The performative verb 'join' is a polite verb unlike the verb 'defeat'. Headline 18 is a directive act that is more of a request. Request, as Trosborg (1995: 187) claims, is considered as "an illocutionary act whereby a speaker conveys to a hearer that he/she wants the hearer to perform an act which is for the benefit of the speaker". The NGP headline above certainly draws our attention to one of the prevailing societal issues in the country- corruption. The NGP headline indicates a speaker performing a directive act that is more of a request or an invitation than an order and which he would like to be complied with in his favour or benefit. Here, the given information anchors the request structured in per formative phrase as well- 'join fight against crooks'. This means that the lawyers to whom the request/ invitation is addressed to, should help join in the anti-graft war. Crooks in the context refer to the offenders.

\section{Conclusion}

In this study, so far, through the use of the NGPs, we have assumed that texts represent the world as it is or how the text producer thinks it is. Through a linguistic investigation, we have ascertained that NGP is indeed a language type used by selected Nigerian newspaper headlines. The study has also showcased this linguistic element as a viable language pattern in the construction and interpretation of some acts that are ideologically motivated. Although the newspaper headlines selected as texts for analysis in this study may not have been adequate for this study to construe hypothesis of any sort. However, we assume that this study is a litmus test for further linguistic researches that will throw more light on the functional status of the nominal group element and its communicative function. 


\section{References}

Adegbite, W. (2000) "Pragmatics: some basic principles and procedures." Babajide, A. ed. Studies in English Language. Ibadan: Enicrownfit.

Arnold, E.( 1985) An introduction to functional grammar. London: Routledge.

Bloor, T, and Bloor, M. (2004).The functional analysis of English. 2nd ed. London: Edward Arnold.

Crystal, D. (2008).Texting the Gr8Db8. Oxford: Oxford University Press.

Fairclough, N. (1989). Language and power.London: Longman

Halliday M.A.K. (1978). Language as a social semiotics: the social interpretation of language and meaning. London: Edward Arnold.

Halliday M.A.K(1985). An introduction to functional grammar. London: Edward Arnold.

Halliday M.A.K(1994). An introduction to functional grammar. 2nd ed. London: Edward Arnold.

Halliday M.A.K(2004). An introduction to functional grammar. 3rd ed. London: Arnold.

Haverkate, H. (1969). Speech act, speakers and hearers. Publishing Company.

Leech, G. and Short, M. (1981). Style in fiction: a linguistic introduction to English fictional prose. Essex Longman Group.

Malmkjær, K. Ed.(1991). The linguistics encyclopaedia. London \& New York: Routledge.

Morley, G. (1985), An introduction to systemic grammar. London: Macmillan.

Okunna, Chinyere, Kate Omenugha and UcheEbeze.. 2002.Writing for the mass media in teaching mass communication: a multi-dimensional approach. Enugu: New Generation Ventures Ltd.,

Onuigbo, S. (2007).Pragmatics of intonation.Anasidu, B.N, Nwaozuzu, S. and Okebalama,

C,N.eds. Language and literature in developing countries. Onitsha: African-First Publisher

Ltd, pp316-325.

Taiwo, R. (2004). "Speech as headline in Nigerian newspapers". SegunAwonus and E. A.Babalola,eds.The domestication of English in Nigeria. Lagos: University of Lagos Press323 -335.

Thompson, G.(2000)Introducing functional grammar. London: Hodder Headline Group.

Trosborg, A. (1995). Inter language pragmatics. Requests, complaints and apologies. Berlin: Moutonde Gruyter. 